\section{Intrauterine growth standards: a cross-sectional study in a population of Nigerian newborns}

\author{
Olugbenga A. Mokuolu, 1 \\ Omotayo O. Adesiyun, \\ Mohammed B. Suleiman, 2 \\ Mustapha Bello 3 \\ 1Department of Paediatrics and Child \\ Health, University of Ilorin; ${ }^{2}$ Department \\ of Paediatrics, Federal Medical Centre, \\ Katsina; ${ }^{3}$ Department of Paediatrics \\ University of Maiduguri Teaching \\ Hospital, Nigeria
}

\section{Abstract}

The aim of the study was to define an intrauterine growth curve for a population of Nigerian newborn babies. A cross-sectional observational study design was adopted. Weight, length and head circumference were all measured in consecutive singleton deliveries at the University of Ilorin Teaching Hospital over a 3 -year period. Gestational age (GA) of the babies was estimated from the last menstrual period or first trimester ultrasound. The estimates obtained were clinically validated using the Ballard score. Mean birth weights and percentiles of the weight, length and head circumferences for the respective GA were estimated using the SPSS 15 software package. A total of 5273 babies were recruited for the study with GA ranging from 25-44 weeks. Comparison of the mean birth weights of the various GA with the data from Denver, Colorado, showed that Nigerian babes tended to weigh less at the early GA, although these differences were not statistically significant. Between 26-36 weeks, the average weights of both sexes were similar; however, beyond this time point there was a consistent increase in the average weight of the males over the female babies. Growth curves for Nigerian newborn babies were generated and showed that the mean birth weight of Nigerian preterm babies was lighter than that of babies in Colorado. The impact of these differences on the classification of newborns will require further evaluation.

\section{Introduction}

For proper classification, the birth weight and gestational age (GA) of all newborns must be plotted according to an appropriate standard. ${ }^{1}$ This has been the practice in most new- born units over the last 40 years. As was observed by Thomas et al., ${ }^{2}$ this practice has been based on the recognition that variance in GA (small or large for gestational age) predicts short-term morbidity and mortality.

Anthropometric parameters, particularly birth weight in relation to GA distribution, may vary from one population to another. Some of the reasons for this variability include socioeconomic factors, race, altitude, and incidence of environmental factors, such as smoking and time of year, which affect the birth weight. - $^{3-6}$

The most widely available intrauterine growth charts are those constructed over three decades ago.7,8 There are, however, important limitations to the use of these charts in Nigeria. This is because they were either derived mainly from a population of Caucasian babies or at high altitudes; ${ }^{7}$ neither are typical characteristics of the Nigerian newborn. Baby birth weight has been reported from various parts of Nigeria but a standard growth chart has not been evolved for use in this country.9-11 In 1981, Olowe developed an intrauterine chart from a small population of Nigeria children, largely using a sample of only 436 patients from the country's commercial city of Lagos. ${ }^{12}$ This chart has, therefore, not been widely used in the country and most newborn units continue to use the Lubchenco chart.?

Various studies have, however, shown that failure to account for racial differences in rates of intrauterine growth when these charts derived from Caucasians are used, leads to inaccurate diagnosis of fetal growth abnormalities in those non-Caucasian newborn. ${ }^{13-16}$ These studies have observed that, on average, non-white infants are smaller at birth than white infants. These differences persist after the data are controlled for such variables as nutrition, pre-natal care and socio-economic status. ${ }^{17}$ Growth charts are now available for various countries and populations within the same country.17-19 These charts are usually population-based and produced according to gender, race and type of delivery. ${ }^{20,21}$

The objective of this study was to generate birth weight for GA curves in a population of Nigerian newborn to guide the appropriate classification of these babies. It will also provide a basis for comparison of birth weights with results from other parts of the world in order to determine the appropriateness or otherwise of growth curves developed in other populations.

\section{Materials and Methods}

\section{Study site}

This study was carried out at the University of Ilorin Teaching Hospital, in Ilorin, the Kwara state capital. The city is located in the
Correspondence: Olugbenga A. Mokuolu, Department of Paediatrics and Child Health, University of Ilorin, PMB 1515, Nigeria.

Tel. +234.803 .7134707$

E-mail: mokuolu@unilorin.edu.ng

Key words: newborn, intrauterine growth pattern.

Conflict of interests: the authors report no potential conflict of interests.

Received for publication: 29 0ctober 2011.

Revision received: 20 July 2012.

Accepted for publication: 20 July 2012.

This work is licensed under a Creative Commons Attribution NonCommercial 3.0 License (CC BYNC 3.0).

(C) Copyright O.A. Mokuolu et al., 2012

Licensee PAGEPress, Italy

Pediatric Reports 2012; 4:e29

doi:10.4081/pr.2012.e29

middle belt region of Nigeria with vegetation consisting mainly of grassland, characteristic of Guinea Savanna. The hospital is $290 \mathrm{~m}$ (957 $\mathrm{ft}$ ) above sea level. Although it is a tertiary institution, it also provides significant primary and secondary health care services to the state. There are an average 2000 deliveries a year.

\section{Study design}

This was a cross-sectional observational study. Consecutive singletons born alive in the hospital from January 2004 to December 2006 were included in the study.

\section{Enrollment and data collection}

Babies included in the studies were from singleton gestation. Babies were excluded if there was antenatal documentation of intrauterine growth retardation or major maternal medical conditions, such as sickle cell disease, cardiac abnormalities, severe hypertension in pregnancy or maternal diabetes irrespective of level of control of the diabetes. The babies were weighed either immediately after birth or as soon as feasible if there was a need for resuscitation (usually within the first hour of delivery). They were weighed on a bassinet scale (Waymaster) and their weight was recorded to the nearest gram. The scales were standardized and were checked daily for zero error. Length and head circumference were measured by the trained midwife using a nonelastic tape; both were recorded to the nearest tenth of a centimeter. GA was calculated from the first day of the mother's last menstrual period when known or from the first trimester ultrasound when available. A clinical assessment of GA was also made using the New Ballard Score.22 Babies were excluded if the 
discrepancies between the GA calculated by date and by Ballard score were in excess of two weeks. The study neonatologists decided on the best estimate of the GA and these were recorded as number of completed weeks. Stillbirths, products of multiple gestation, and babies with major congenital anomalies were excluded.

\section{Statistical methods}

Data on anthropometric parameters were entered into the EPI-info statistical package (version 6.04d) and cleaned for errors. Data were subsequently exported and analyzed with SPSS statistical package (15.0 version). For each GA, the means and percentiles of the weight, length and occipito-frontal circumfer-

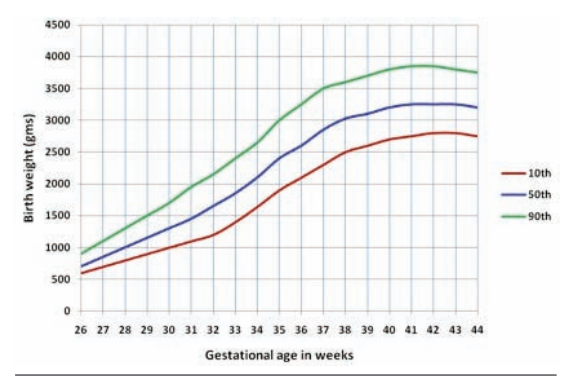

Figure 1. Birth weight for gestational age curves in a population of Nigerian newborns.

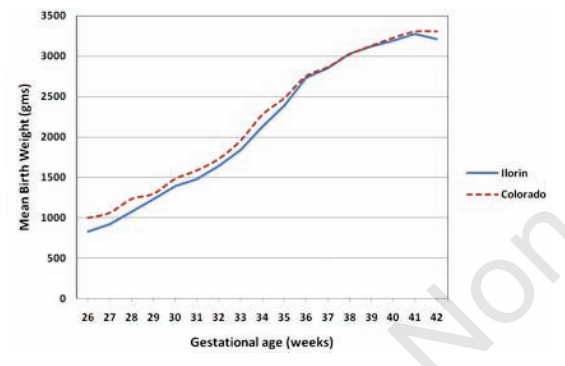

Figure 2. Comparison of mean birth weights between Ilorin and Colorado.

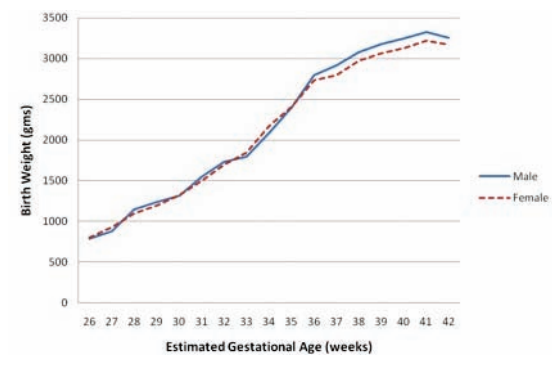

Figure 3. Comparison of the mean birth weights by gender.

Table 1. Weight percentiles by gestational age categories.

\begin{tabular}{lcccccc}
\hline Estimated GA (wks) & Number & \multicolumn{5}{c}{ Percentiles } \\
& & 10 & 25 & 50 & 75 & 90 \\
26 & 14 & 650 & 663 & 700 & 1038 & 1100 \\
27 & 12 & 700 & 850 & 950 & 1100 & 1200 \\
\hline 28 & 32 & 855 & 913 & 1000 & 1250 & 1300 \\
29 & 26 & 955 & 1100 & 1250 & 1350 & 1500 \\
\hline 30 & 50 & 1100 & 1250 & 1300 & 1450 & 1750 \\
31 & 35 & 1240 & 1300 & 1450 & 1525 & 1820 \\
\hline 32 & 93 & 1285 & 1388 & 1575 & 1763 & 2130 \\
33 & 79 & 1500 & 1688 & 1950 & 2105 & 2350 \\
\hline 34 & 112 & 1640 & 1838 & 2100 & 2313 & 2610 \\
35 & 110 & 1800 & 2150 & 2500 & 2700 & 2900 \\
\hline 36 & 280 & 2000 & 2300 & 2600 & 3000 & 3250 \\
37 & 405 & 2290 & 2600 & 2850 & 3100 & 3500 \\
\hline 38 & 879 & 2500 & 2800 & 3025 & 3350 & 3600 \\
39 & 1027 & 2600 & 2850 & 3100 & 3400 & 3700 \\
\hline 40 & 1273 & 2650 & 2900 & 3200 & 3500 & 3750 \\
41 & 515 & 2735 & 3000 & 3250 & 3550 & 3850 \\
\hline 42 & 238 & 2550 & 2900 & 3100 & 3500 & 3750 \\
43 & 74 & 2670 & 2838 & 3175 & 3300 & 3630 \\
\hline 44 & 19 & 2800 & 2863 & 3100 & 3238 & 3470 \\
Total & 5273 & & & & & \\
\hline 645 & & & & & &
\end{tabular}

GA, gestational age.

Table 2. Length percentiles by gestational age categories.

\begin{tabular}{|c|c|c|c|c|c|c|}
\hline Estimated GA (wks) & Number & & & cent & & \\
\hline & & 10 & 25 & 50 & 75 & 90 \\
\hline 26 & 14 & 28.0 & 31.0 & 31.0 & 33.3 & 34.5 \\
\hline 27 & 12 & 30.0 & 33.0 & 33.0 & 36.0 & 38.0 \\
\hline 28 & 32 & 33.2 & 35.3 & 37.5 & 38.0 & 39.8 \\
\hline 29 & 26 & 35.0 & 35.3 & 39.0 & 40.0 & 41.0 \\
\hline 30 & 50 & 35.0 & 37.0 & 39.0 & 41.0 & 43.0 \\
\hline 31 & 35 & 35.0 & 37.0 & 40.0 & 42.5 & 44.8 \\
\hline 32 & 93 & 36.0 & 38.0 & 40.0 & 43.0 & 45.0 \\
\hline 33 & 79 & 40.0 & 42.0 & 43.5 & 46.0 & 47.5 \\
\hline 34 & 112 & 40.0 & 43.0 & 44.5 & 47.0 & 48.1 \\
\hline 35 & 110 & 42.8 & 44.0 & 46.0 & 48.0 & 50.0 \\
\hline 36 & 280 & 43.0 & 45.0 & 47.0 & 49.0 & 51.0 \\
\hline 37 & 405 & 44.0 & 46.0 & 48.0 & 50.0 & 52.0 \\
\hline 38 & 879 & 45.0 & 47.0 & 49.0 & 50.0 & 52.0 \\
\hline 39 & 1027 & 46.0 & 47.0 & 49.0 & 50.0 & 52.0 \\
\hline 40 & 1273 & 46.0 & 48.0 & 49.0 & 51.0 & 52.0 \\
\hline 41 & 515 & 46.0 & 48.0 & 50.0 & 51.0 & 53.0 \\
\hline 42 & 238 & 46.0 & 48.0 & 49.0 & 51.0 & 52.0 \\
\hline 43 & 74 & 47.0 & 48.0 & 49.0 & 51.0 & 53.0 \\
\hline 44 & 19 & 45.6 & 47.0 & 48.0 & 49.8 & 50.7 \\
\hline Total & 5273 & & & & & \\
\hline
\end{tabular}


Table 3. Occipito-frontal circumference percentiles by gestational age categories.

\begin{tabular}{|c|c|c|c|c|c|c|}
\hline \multirow{2}{*}{ Estimated GA (wks) } & \multirow[t]{2}{*}{ Number } & \multicolumn{5}{|c|}{ Percentiles } \\
\hline & & 10 & 25 & 50 & 75 & 90 \\
\hline 26 & 14 & 22.0 & 22.0 & 22.5 & 24.0 & 26.0 \\
\hline 27 & 12 & 23.0 & 24.0 & 25.0 & 26.0 & 27.5 \\
\hline 28 & 32 & 23.5 & 25.0 & 26.0 & 27.0 & 28.8 \\
\hline 29 & 26 & 24.5 & 26.3 & 28.0 & 29.0 & 31.0 \\
\hline 30 & 50 & 25.0 & 26.0 & 28.0 & 29.0 & 31.0 \\
\hline 31 & 35 & 26.2 & 27.5 & 28.0 & 29.5 & 31.0 \\
\hline 32 & 93 & 27.4 & 28.0 & 29.0 & 31.0 & 32.0 \\
\hline 33 & 79 & 28.5 & 30.0 & 31.0 & 32.0 & 33.0 \\
\hline 34 & 112 & 29.0 & 31.0 & 32.0 & 33.0 & 34.0 \\
\hline 35 & 110 & 31.0 & 32.0 & 33.0 & 34.0 & 35.2 \\
\hline 36 & 280 & 32.0 & 32.0 & 34.0 & 35.0 & 36.0 \\
\hline 37 & 405 & 32.0 & 33.0 & 34.0 & 35.0 & 36.0 \\
\hline 38 & 879 & 32.0 & 33.0 & 34.0 & 36.0 & 36.0 \\
\hline 39 & 1027 & 32.0 & 34.0 & 35.0 & 36.0 & 37.0 \\
\hline 40 & 1273 & 33.0 & 34.0 & 35.0 & 36.0 & 37.0 \\
\hline 41 & 515 & 33.0 & 34.0 & 35.0 & 36.0 & 37.0 \\
\hline 42 & 238 & 33.0 & 34.0 & 35.0 & 36.0 & 37.0 \\
\hline 43 & 74 & 33.0 & 34.0 & 35.0 & 36.0 & 38.0 \\
\hline 44 & 19 & 33.0 & 34.0 & 35.0 & 36.0 & 38.0 \\
\hline Total & 5273 & & & & & \\
\hline
\end{tabular}

ence were determined. Smoothed curves of the intrauterine pattern of the various parameters were constructed using the $10^{\text {th }}, 50^{\text {th }}$ and $90^{\text {th }}$ percentiles.

\section{Results}

A total of 5275 babies were recruited to the study with birth weights ranging from 400 to $4300 \mathrm{~g}$. GA ranged from 24 to 45 weeks. One baby had GA of 24 weeks, and one had GA of 45 weeks; both of these babies were excluded from the data analysis. Of the 5273 analyzed, 844 (16\%) were pre-term, 4334 (82.2\%) were term while $95(1.8 \%)$ were post-term. There were 2690 (51\%) males and 2583 (49\%) females. There was insufficient representation of newborns with GA under 26 weeks.

Tables 1-3 show the distribution of the babies according to GA and the percentile intervals of their weight, length and head circumference. Figure 1 reflects the smoothed curves for the $10^{\text {th }}, 50^{\text {th }}$ and $90^{\text {th }}$ of the weights for the respective $\mathrm{GA}$.

Figure 2 shows the comparison of the mean birth weights for our study and that of Lubchenco et al. 7 The comparison of the average growth curves with that of the Lubchenco chart showed that the babies in these studies were generally lighter at the early stages of gestation while this difference was virtually nil at term. Thereafter, the average growth curve had a steep decline for the post-term category but this was not measured in the Colorado study and, therefore, no comparison could be made. With respect to gender, the data showered a fairly similar growth curve at the early weeks of gestation from 26-36 weeks. However, beyond this point there was a consistent increase in the average weight of the male babies compared to the females (Figure 3 ).

\section{Discussion}

The importance of the intrauterine growth curve described by Lubchencho, et al.,7 Usher and McLean over three decades ago is proved by the fact that they are still used in neonatal units today. ${ }^{8}$ They serve as standard references to classify newborns as small for GA, appropriate for GA and large for GA. Incorrect classification may then lead to failure in recognizing those at risk or lead to unnecessary tests and treatment in normal babies.

This study revealed two important characteristics in relation to the Lubchenco chart. The first is that for GA of less than 37 weeks, the babies tended to weigh less. Secondly, there was a sharp decline in the weight for GA immediately pregnancy went beyond 42 com- pleted weeks of gestation. The Lubchenco chart did not report the weight of babies born after 42 weeks. Babies weighed less despite the study having been conducted practically at sea level compared with Denver, Colorado (5000 $\mathrm{ft}$ above sea level), and this may be in agreement with observations by Thomas et al. ${ }^{2}$ In their study by the Pediatrix medical group, these authors found altitude as an independent variable might not significantly affect birth weight. This was a multicenter study carried out in 85 neonatal units at various altitudes (below or over 4000 feet) in the United States. The group also found that race is important as black babies were found to weigh less than white babies. It was suggested that this reflected either a biological or a pathological effect as black mothers were more prone to pregnancyassociated hypertension. However, the current study did not consider the effect of hypertension and only included black babies. It is, however, unlikely that hypertension would be the basis of the observed decline in birth weight. It would have been expected that the impact of hypertension in pregnancy on the fetal weight should increase with GA.23,24 This was not found in the current study. Instead, the authors found a more divergent mean birth weight with younger fetal age while hardly any divergence was seen from 37 through to 42 weeks of gestation. It is, therefore, more probable that this is a reflection of racial or other socio-biological differences in the early fetal growth pattern. With respect to the marked reduction in the weight percentiles after 42 weeks gestation, there were no data with which to compare this category. There were also very few babies in this category with the possibility of underrepresentation. However, the decline in weight for this GA category is not totally unexpected. The sharp decline in birth weight of post-term babies is largely associated with placental insufficiency. 25 This justifies the $42^{\text {nd }}$ week expectative management of pregnancies with GA beyond 40 weeks. $^{26}$

\section{Conclusions}

An intrauterine growth curve for Nigerian babies has been developed. Comparison with curves developed in Denver, Colorado, showed that Nigerian pre-term babies weighed slightly less than the Caucasian babies, the implication being that use of the Lubchenco chart in classifying Nigerian newborn may result in some babies being wrongly classified with consequent implications. However, the impact of these differences in the mean birth weight on the newborn classification requires further evaluation. 
live-born Caucasian infants at sea level: standards obtained from measurements in 7 dimensions of infants born between 25 and 44 weeks of gestation. J Pediatr 1969; 74:901-10.

1. American Academy of Pediatrics. Committee on fetus and newborn. Nomenclature for duration of gestation, birth weight and intra-uterine growth. Pediatrics 1967;39:935-9.

2. Thomas P, Peabody J, Turnier V, Clark RH. A new look at intrauterine growth and the impact of race, altitude, and gender. Pediatrics 2000;106:E21.

3. Kleijer ME, Dekker GA, Heard AR. Risk factors for intrauterine growth restriction in a socio-economically disadvantaged region. J Matern Fetal Neonatal Med 2005;18:23-30.

4. Balcazar H, Keefer L, Chard T. Use of anthropometric indicators and maternal risk factors to evaluate intrauterine growth retardation in infants weighing more than 2500 grams at birth. Early Hum Dev 1994;36:147-55.

5. Cnattingius S, Axelsson 0, Eklund G, et al. Factors influencing birthweight for gestational age, with special respect to risk factors for intrauterine growth retardation. Early Hum Dev 1984;10:45-55.

6. Fulford AJ, Rayco-Solon P, Prentice AM. Statistical modelling of the seasonality of preterm delivery and intrauterine growth restriction in rural Gambia. Paediatr Perinat Epidemiol 2006;20:251-9.

7. Lubchenco L0, Hansman C, Dressler M, Boyd E. Intrauterine growth as estimated from liveborn birth-weight data at 24 to 42 weeks of gestation. Pediatrics 1963; 32:793-800.

8. Usher R, McLean F. Intrauterine growth of

9. Ogbeide 0, Alakija W. Birthweights of babies in Benin, Bendel State of Nigeria. J Trop Pediatr 1985;31:139-42.

10. Osuhor PC. Birthweights in southern Zaria, Northern Nigeria. J Trop Pediatr 1982;28:196-8.

11. Effiong CE, Laditan AA, Aimakhu VE, Ayeni 0 . Birthweights of Nigerian children. Niger Med J 1976;6:63-8.

12. Olowe SA. Standards of intrauterine growth for an African population at sea level. J Pediatr 1981;99:489-95.

13. Morse SB, Wu SS, Ma C, et al. Racial and gender differences in the viability of extremely low birth weight infants: a population-based study. Pediatrics 2006; 117(1):e106-12.

14. Madan A, Holland S, Humbert JE, Benitz WE. Racial differences in birth weight of term infants in a northern California population. J Perinatol 2002;22:230-5.

15. Ranganathan D, Wall S, Khoshnood B, et al. Racial differences in respiratory-related neonatal mortality among very low birth weight infants. J Pediatr 2000;136: 454-9.

16. James SA. Racial and ethnic differences in infant mortality and low birth weight. A psychosocial critique. Ann Epidemiol 1993; 3:130-6.

17. Kramer MS, Ananth CV, Platt RW, Joseph KS. US black vs white disparities in foetal growth: physiological or pathological? Int J Epidemiol 2006;35:1187-95.
18. Roberts CL, Lancaster PA. Australian national birthweight percentiles by gestational age. Med J Aust 1999;170:114-8.

19. Katzman GH, Satish M. Screening term LGA neonates for hypoglycemia: the Colorado vs. the Portland intrauterine growth chart. J Perinatol 1987;7:44-6.
20. Roberts CL, Lancaster PA. National birthweight percentiles by gestational age for twins born in Australia. J Paediatr Child Health 1999;35:278-82.

21. Glinianaia SV, Skjaerven R, Magnus P. Birthweight percentiles by gestational age in multiple births. A population-based study of Norwegian twins and triplets. Acta Obstet Gynecol Scand 2000;79:450-8.

22. Ballard JL, Khoury JC, Wedig K, et al. New Ballard score, expanded to include extremely premature infants. J Pediatr 1991; 119:417-23.

23. Lau TK, Pang MW, Sahota DS, Leung TN. Impact of hypertensive disorders of pregnancy at term on infant birth weight. Acta Obstet Gynecol Scand 2005;84:875-7.

24. Waugh J, Perry IJ, Halligan AW, et al. Birth weight and 24-hour ambulatory blood pressure in nonproteinuric hypertensive pregnancy. Am J Obstet Gynecol 2000;183:6337.

25. Tsukada I. [Management of post-term pregnancy]. Nippon Sanka Fujinka Gakkai Zasshi 1986;38:1263-8. [Article in Japanese].

26. Maly Z, Grosmanova A, Pulkrabkova S, Gogela J. [Effect of birth weight on neonatal and maternal morbidity in expectant management of post-term pregnancy]. Ceska Gynekol 2002;67Suppl1:20-2. [Article in Czech]. 